\title{
Minimally invasive image-guided therapies for hepatocellular carcinoma
}

This article was published in the following Dove Press journal:

Journal of Hepatocellular Carcinoma

II October 2016

Number of times this article has been viewed

\author{
Mohamed E Abdelsalam' \\ Ravi Murthy' \\ Rony Avritscher' \\ Armeen Mahvash' \\ Michael J Wallace' \\ Ahmed O Kaseb ${ }^{2}$ \\ Bruno C Odisio' \\ 'Department of Interventional \\ Radiology, ${ }^{2}$ Department of Medical \\ Oncology, The University of Texas \\ MD Anderson Cancer Center, \\ Houston, TX, USA
}

Correspondence: Mohamed E Abdelsalam Department of Interventional Radiology, Unit I47I, The University of Texas MD Anderson Cancer Center, 1515 Holcombe Blvd., Houston,

TX 77030-4009, USA

$\mathrm{Tel}+|7| 3563 \quad 1065$

Fax +I 713 7924098

Email meabdelsalam@mdanderson.org

\begin{abstract}
Hepatocellular carcinoma (HCC) is the fifth most frequently occurring cancer globally and predominantly develops in the setting of various grades of underlying chronic liver disease, which affects management decisions. Image-guided percutaneous ablative or transarterial therapies have acquired wide acceptance in HCC management as a single treatment modality or combined with other treatment options in patients who are not amenable for surgery. Recently, such treatment modalities have also been used for bridging or downsizing before definitive treatment (ie, surgical resection or liver transplantation). This review focuses on the use of minimally invasive image-guided locoregional therapies for HCC. Additionally, it highlights recent advancements in imaging and catheter technology, embolic materials, chemotherapeutic agents, and delivery techniques; all lead to improved patient outcomes, thereby increasing the interest in these invasive techniques.
\end{abstract}

Keywords: hepatocelleular carcinoma, locoregional therapy, TACE, ablation, ${ }^{90} \mathrm{Y}$

\section{Introduction}

Despite progress in the diagnosis and management of hepatocellular carcinoma (HCC), the incidence and fatality rate are still growing in many countries. Currently, HCC is the fifth most frequently occurring cancer and the third largest contributor to cancer-related mortality worldwide. ${ }^{1}$ HCC predominantly develops in the presence of underlying liver cirrhosis rendering its management relatively challenging compared with therapy for other tumors; thus, HCC is managed through a multidisciplinary approach involving various subspecialties including surgery, hepatology, medical oncology, interventional radiology, pathology, and radiation oncology.

Since HCC is considered a two-disease entity because of the presence of HCC tumors and chronic liver disease, all HCC staging systems rely on parameters related to both the tumor stage and the hepatic function. Although many HCC staging systems have been proposed, the Barcelona Clinic Liver Cancer (BCLC) staging system has gained wide acceptance in clinical practice and in many clinical trials. The BCLC system is considered a treatment allocation system; therefore, once the patient has been assigned a BCLC stage, the suitable treatment options are determined. The known factors such as survival predictors, radiologic tumor extension, hepatic functional reserve, and performance status are all included in the BCLC staging system. Hence, patients with BCLC stages $\mathrm{A}$ and $\mathrm{B}$ are now considered the standard candidate patient population for locoregional HCC therapies. ${ }^{2}$ We performed literature search on English language publications in the PubMed database using the terms hepatocellular carcinoma, locoregional therapy, 
TACE, and ablation. This article focuses on minimally invasive image-guided locoregional therapies for HCC. Minimally invasive locoregional therapies (such as percutaneous ablative therapies and transarterial catheter-based techniques) have gained wide acceptance as monotherapy or in combination with other local or systemic treatment modalities in patients who are not surgical candidates or as a bridging or downsizing modality before definitive treatment (ie, surgical resection or liver transplantation).

\section{Percutaneous ablative therapies Percutaneous chemical ablation}

Percutaneous ethanol injection (PEI) is the seminal ablative technique. Absolute ethanol is injected directly in the tumor through a guiding needle, resulting in coagulative necrosis. The best results are achieved in tumors up to $2 \mathrm{~cm}$ in diameter. ${ }^{3-5}$ The distribution of the ethanol within tumor may be affected by intra-tumoral septae and/or capsule, and this may be responsible for suboptimal response in larger lesions. Currently, PEI should be considered when radiofrequency ablation (RFA) is not feasible as in case of lesions close to important structures that are of concern for damage with thermal ablation. ${ }^{2}$

\section{Percutaneous radiofrequency ablation}

Although PEI was first introduced for the management of HCC, current data support using RFA rather than PEI for HCC given the superiority of RFA owing to fewer treatment sessions, shorter hospital stays, better local disease control, higher amounts of tumor necrosis, and improved progression-free survival and overall survival (OS) ${ }^{6,7}$ RFA induces coagulative necrosis resulting from the thermal energy created by the delivery of alternating electrical currents through the electrode needle placed in the tumor. The heat generated in the vicinity of the electrode is then conducted to the surrounding environment, not limited by septa or capsulation, resulting in coagulative necrosis of a finite tissue volume. The tissue surrounding the tip of the electrode is destroyed within seconds as the temperature reaches $55^{\circ} \mathrm{C}-60^{\circ} \mathrm{C}$, and then the thermal energy disseminates to the surrounding tissue ideally to cover $0.5-1 \mathrm{~cm}$ of normal tissue surrounding the tumor. ${ }^{8}$

RFA is effective in the treatment of small HCC tumors ( $<3 \mathrm{~cm}$; very early-stage disease and early-stage disease using the BCLC system). Although according to the BCLC system, resection is the modality of choice in very early-stage disease, there is no clear consensus on whether ablation or surgical resection is better for surgically feasible patients with small HCC tumors. Several nonrandomized and randomized controlled studies have compared ablative therapies with surgical resection for small HCC treatment. ${ }^{9-15}$ In a randomized clinical trial including 105 patients with $114 \mathrm{HCC}$ nodules, Lu et al compared surgical resection to percutaneous ablation (RFA and microwave ablation). The investigators concluded that in addition to minimal invasiveness, accessibility, and cost savings, percutaneous ablation achieved a therapeutic effect and 3-year survival outcomes equivalent to those of surgical resection. They suggested that RFA may be considered as one of the first-choice modalities for treating early-stage HCC. ${ }^{16}$ In a more recent study, Feng et al reported that in patients with $\mathrm{HCC}$ nodules (up to 2 ) $<4 \mathrm{~cm}$ $(n=168)$, the therapeutic effectiveness of RFA and surgical resection were similar with no statistical difference in the OS and recurrence-free survival between both the groups. ${ }^{15} \mathrm{Zhou}$ et al conducted a meta-analysis of 4 randomized controlled trials comparing percutaneous RFA with surgical resection for small HCC reported between 1990 and 2010. The differences in OS between RFA and surgical resection were not statistically significant $(P>0.05) .{ }^{11}$ In addition, Livraghi et al conducted a cohort study and retrospectively reviewed a prospective multicenter database of 218 patients with a single $\mathrm{HCC}(<2 \mathrm{~cm})$ treated with RFA. The authors reported that a sustained complete response and the 5-year survival rate were observed in $97.2 \%$ and was $68.5 \%$, respectively, comparable to that of surgical resection. The investigators concluded that RFA can be the treatment of choice, even in surgical candidates, whereas surgical resection can be considered in cases not amenable for RFA. ${ }^{17}$

\section{Percutaneous microwave ablation}

Microwave ablation is a promising thermal ablation technology that can be used as an alternative to RFA to treat HCC. Multiple microwave ablation systems are currently available in the US market and have been approved for clinical practice. During microwave ablation, coagulative necrosis is induced through the application of electromagnetic waves through the antenna (ie, microwave probe). The transmitted energy induces rapid molecular agitation and friction, leading to a significant increase in the temperature of water and heat conduction to the surrounding target tissue, thereby resulting in cell death and coagulative necrosis. ${ }^{18}$ Microwave ablation offers several advantages over other forms of ablation, ${ }^{19}$ such as high thermal efficiency resulting in larger ablation volumes, a higher capability of coagulating blood vessels, a faster ablation time, and a less severe heat sink effect. ${ }^{19}$

Poggi et $\mathrm{a}^{20}$ treated $194 \mathrm{HCC}$ lesions in 144 patients using microwave ablation. The average diameter of the lesions was 
$2.7 \mathrm{~cm}$ (68 lesions $>3 \mathrm{~cm}$ ). Complete response was obtained in $100 \%$ of small HCCs and $94.3 \%$ of all the lesions. After a median of 19.5-month follow-up, local tumor progression was noted in 5.1\% (10 lesions). No major complications occurred, minor complications were reported in $5.1 \%$ procedures. ${ }^{20}$ Zhang et $\mathrm{al}^{21}$ evaluated the therapeutic efficacy of percutaneous RFA versus microwave ablation for HCCs measuring up to $5 \mathrm{~cm}$. Complete ablation was achieved in $83.4 \%$ (78/93) and $86.7 \%$ (91/105) of cases were treated with RFA and microwave ablation, respectively. The tumor progression rate was $11.8 \%$ $(11 / 93)$ in the cases treated with RFA and $10.5 \%(11 / 105)$ in those treated with microwave ablation. There was no statistically significant difference in the OS rates $(P=0.780)$ or the disease-free survival rates $(P=0.123)$ between both the modalities. The authors concluded that RFA and microwave ablation are equally effective in treating $\mathrm{HCC}$, with no significant differences in complete ablation, local tumor progression, and OS. ${ }^{21}$

\section{Percutaneous cryoablation}

During cryoablation, a probe is inserted directly into the target lesion to reduce its temperature $\left(-20^{\circ} \mathrm{C}\right.$ to $\left.-40^{\circ} \mathrm{C}\right)$, creating an ice ball that can be monitored by imaging. The resultant low temperature in the target tissue is lethal and causes cell death. In addition, alternating cooling and thawing add more cytotoxic effects through different mechanisms. Cryoablation has limited application in HCC. Lee et $\mathrm{al}^{22}$ studied percutaneous cryoablation for $20 \mathrm{HCCs}(<3 \mathrm{~cm})$ in 20 patients who were not surgical candidates. Technical success was achieved in all the procedures, and no complications were reported. At 1-month follow-up, computed tomography revealed complete response, partial response, stable disease in 13, 4, and 3 patients, respectively. None of the patients had progressive disease. After a mean of 20.7-month follow-up (6-30 months), one of the 13 lesions ( $8 \%$ ) developed local recurrence. ${ }^{22}$ Nevertheless, the potential serious complications following cryoablation cannot be neglected, such as "cryoshock," a systemic inflammatory response resulting in multiorgan failure. ${ }^{23-25}$

\section{Percutaneous transarterial therapies}

HCCs derive most of their vascular supply from the hepatic artery, contrary to most of the normal liver, which derives blood supply from the portal vein. This is the rationale behind the transarterial therapies during which the delivery of therapeutic agents and/or the blockage of the supplying vessels is attempted.

\section{Transarterial chemoembolization}

For conventional transarterial chemoembolization (cTACE), one or more chemotherapeutic drugs, most commonly doxorubicin and cisplatin, are added to lipiodol and delivered to the feeding arteries of the tumor. Following this, an embolic agent is administered in the feeding arteries to minimize the tumor washout of the chemotherapeutic mixture and induce ischemic necrosis.

Recently, the use of calibrated microspheres loaded with chemotherapeutic agents has gained wide acceptance. During TACE with drug-eluting beads (DEB-TACE), the microspheres deposited within the tumor elute the loaded drug over time, resulting in very low levels of the chemotherapeutic agent in the systemic circulation and conveyance of high-dose chemotherapy to the tumor with more definite distal blockage of small vessels. ${ }^{26,27}$

According to BCLC guidelines, TACE is considered the treatment of choice for intermediate stage disease (stage B). In a meta-analysis of randomized clinical trials of unresectable HCC, Llovet et al showed that TACE improved survival compared with the best supportive care. ${ }^{28}$ In a study published by Burrel et al, patients classified as BCLC-B who underwent DEB-TACE had a median survival of 42.8 months after censoring follow-up at the time of liver transplantation, chemotherapy treatment (sorafenib), and radioembolization. ${ }^{29}$ More recently, TACE has also been used for bridging and downstaging in HCC patients prior to liver transplantation. Bridging refers to the use of TACE for patients who meet transplantation criteria and are on the transplant list. In a multicenter study evaluating the impact of preoperative locoregional treatments on recurrence-free survival following hepatic transplantation for $\mathrm{HCC}$, the 5-year recurrencefree survival rate in the subgroup with pathologic $\mathrm{T} 2$ or T3 HCC was $93.8 \%$ and $80.6 \%$ in patients who underwent locoregional therapy and in patients who did not receive any treatment, respectively. ${ }^{30}$

Downstaging refers to patients who do not meet the criteria for orthotopic liver transplantation owing to the extent of disease according to the current including criteria and receive any locoregional therapy in an attempt to reduce the extent of the disease, ultimately becoming eligible for the liver transplantation. In a prospective study investigating the use of locoregional therapy to downstage HCC prior to liver transplantation, Yao et al revealed that downstaging was achieved in $70 \%$ of patients who subsequently underwent liver transplantation. ${ }^{31}$

\section{Transarterial bland embolization}

Transarterial catheter-based therapy includes delivery of embolic agent with (TACE) or without (transarterial embolization [TAE]) chemotherapeutic drugs. ${ }^{32}$ In a case-control study including 25 and 50 patients who underwent TAE and TACE, 
respectively, prior to liver transplantation, complete necrosis was achieved in $36 \%$ of the TAE patients and in $26 \%$ of the TACE patients. There was no significant differences between both the groups in the 3 -year OS rates $(P=0.66)$ and the 3 -year recurrence-free survival rates $(P=0.67)$. The investigators concluded that no significant differences were noted in wait-list dropout or in OS or recurrence-free survival between HCC patients undergoing either TAE or TACE before transplantation. ${ }^{33}$ In a more recent single-center randomized phase II trial that included 101 patients, Brown et al $^{34}$ investigated the differences in response (using Response Evaluation Criteria in Solid Tumors criteria) as a primary point between patients who underwent TAE $(n=50)$ and the patients who underwent TACE $(n=51)$. Other secondary assessment points included safety and tolerability, time to progression (TTP), progressionfree survival, and OS. The investigators concluded that no apparent differences were noted between both the groups. ${ }^{34}$

\section{Transarterial radioembolization}

During transarterial radioembolization (TARE), a B-emitter radioactive isotope, yttrium-90 $\left({ }^{90} \mathrm{Y}\right)$, is loaded on microspheres. Like other transcatheter-based treatments, TARE depends on the preferential flow of blood to the hepatic tumors. Thus, compared with traditional external radiation, TARE permits the delivery of a significantly higher radiation dose to the tumor with minimal irradiation to the normal liver parenchyma, thereby minimizing the risk of radiation hepatitis. ${ }^{35,36}$

In the United States, Food and Drug Administration (FDA) has approved two ${ }^{90} \mathrm{Y}$ microsphere products for clinical treatment: TheraSphere (MDS Nordion Inc., Kanata, Ontario, Canada) and SIR-Spheres (SIRTeX Medical Ltd., Sydney, New South Wales, Australia). TheraSphere, consists of glass ${ }^{90} \mathrm{Y}$ microspheres, was approved in the United States for the treatment of patients with HCC. SIR-Spheres, the resin ${ }^{90} \mathrm{Y}$ microspheres, have approval for the treatment of hepatic colorectal metastasis with adjuvant hepatic arterial infusion of floxuridine. However, worldwide, the clinical use of both the ${ }^{90} \mathrm{Y}$ microspheres is more generic, and both are used for HCC therapy.

Although not specified on the BCLC staging and treatment algorithm, TARE is used for intermediate and advanced stage HCC. A recent phase II study investigated the efficacy of TARE (lobar delivery of $120 \mathrm{~Gy}$ ) on patients with intermediate $(n=17)$ and advanced $(n=35)$ HCC. The study included primary endpoint; TTP and secondary endpoints; and tumor response, safety, and OS. After a median of 36 months of follow-up in 52 patients who received 58 treatments, there was no significant difference in TTP between patients with portal vein thrombosis (PVT) and those without PVT (7 vs 13 months).
The median OS was 18 and 13 months in non-PVT and PVT patients, respectively, with an insignificant tendency in favor of non-PVT patients. The authors concluded that TARE is effective for treating intermediate to advanced HCC, particularly for patients with PVT. ${ }^{37}$

In a single-center prospective cohort study, Salem et $\mathrm{al}^{38}$ administered ${ }^{90} \mathrm{Y}$ treatments to 291 patients with $\mathrm{HCC}$ (52\% BCLC-C). The response rates were based on World Health Organization (42\%) and European Association for the Study of Liver criteria (57\%). The overall TTP was 7.9 months. The median survival time was 17.2 months in patients with ChildPugh A and 7.7 months in patients with Child-Pugh B disease $(P=0.002)$. Child-Pugh B patients with PVT survived a median of 5.6 months (95\% confidence interval [CI], 4.5-6.7). ${ }^{38}$

\section{Combined therapies}

Although not described in the HCC treatment algorithm, combined local therapies or combined local and systemic therapies have gained wide recognition in many institutions.

\section{Combined local therapies}

Given the suboptimal response of larger tumors to ablative therapies, several studies have evaluated the combination of ablative therapies with TACE for lesions measuring $3-5 \mathrm{~cm} \cdot{ }^{39-42}$ The combination of TACE and RFA is the most studied combination used for HCC treatment. Two techniques were used: 1) RFA followed by TACE and 2) TACE followed by RFA. The concept behind the former technique is increased delivery of the chemoembolic agent in the ablated tumor periphery, the most common zone for tumor recurrence. ${ }^{43}$ Lencioni et $\mathrm{al}^{43}$ studied this concept in 20 patients with a single HCC measuring 33-70 mm. DEB-TACE was then performed (50-125 mg doxorubicin), and patients were monitored for 6-20 months (mean of 12 months). The volume of treatment-induced necrosis was calculated through imaging. Complete response was achieved after the combined therapy in $60 \%$ of patients, and the volume of necrosis was increased from $48.1 \mathrm{~cm}^{3}$ after RFA to $75.5 \mathrm{~cm}^{3}$ after DEBTACE, with mean increase of $60.9 \%{ }^{43}$

The rationale for the use of TACE preceding RFA is the occlusion of the tumor-supplying vessels decreasing perfusion-mediated tissue cooling classically associated with the heat sink effect in hypervascular tumors. Several studies validated this approach and demonstrated increased therapeutic effect when RFA was performed after TAE or TACE. ${ }^{39,40,44}$ Veltri et a ${ }^{39}$ used this approach to treat 51 HCC lesions (mean $4.89 \mathrm{~cm}$ ) in 46 patients. On the first follow-up CT, complete response was achieved in $85.2 \%$ of the patients $(23 / 27)$ and partial response was achieved in $14.8 \%$ (4/7 patients 
in lesions $<5 \mathrm{~cm}$. In lesions $>5 \mathrm{~cm}$, complete response was achieved in $45.8 \%$ (11/24 patients) and partial response in $54.2 \%$ (11/24 patients). The investigators concluded that combined treatment for non-early HCC yielded a high rate of complete response (particularly in lesions $<5 \mathrm{~cm}$ ). ${ }^{39}$

\section{Combined local and systemic therapies}

Sorafenib, a multikinase inhibitor was approved by the US FDA in 2007 for unresectable or untransplantable HCC with Child-Pugh class A or B. As recommended in the BCLC guidelines, sorafenib is the mainstay for advanced stage HCC (ie, patients who have a branch vein tumoral invasion with or without minimal extra-hepatic disease and a performance status of 1-2). The impact of sorafenib on the OS and TTP was revealed in two randomized control trials. ${ }^{45,46}$ Although not outlined in the BCLC guidelines, several studies have investigated the effectiveness of combining sorafenib with locoregional treatment (TACE or TARE) in intermediate and advanced HCC. ${ }^{47-51}$ A prospective, single-arm, phase II study evaluated the safety of combined TACE and sorafenib on the TTP in 50 patients (BCLC stage B [82\%] and BCLC stage $\mathrm{C}[18 \%])$. Sorafenib was given for 24 consecutive weeks starting 3 days after TACE was administered. Evaluation of the tumor response was performed every 8 weeks. The overall median TTP was 7.1 months $(95 \%$ CI, BCLC stage B [7.3 months] and BCLC stage C [5 months]). The progression-free survival rate at 6 months was $52 \%$ and the median OS was 20.8 months. $^{49}$

Another prospective single-center phase II study evaluated the safety of and response to combined DEB-TACE and sorafenib in unresectable HCC patients $(64 \%$ BCLC stage C). The authors concluded that the sorafenib and DEB-TACE combined therapy in patients with unresectable HCC is safe and well tolerated, with most adverse effects from sorafenib. Most adverse effects were minor (grade 1-2 in 83\% versus grade $3-4$ in 17\%) and manageable with adjustments in the sorafenib dose. ${ }^{48}$

A recent study by Mahvash et al investigated therapy effectiveness, TTP, and survival in 19 patients who received TARE and sorafenib. The median OS was 19.52 and OS rates were $62.3 \%$ and $31.7 \%$ at 1 and 2 years, respectively. The investigators concluded that local response (partial response/ stable disease) was obtained in $100 \%$ of the patients with an increase in the survival when compared with available studies evaluating sorafenib alone in similar patient populations. ${ }^{52}$

\section{Future directions}

Tumor recurrence is a major challenge in the treatment of early-stage HCC. Effective preventive measures in the form of better single locoregional therapy or combined therapies are crucial.

Irreversible electroporation (IRE) is a novel technique for nonthermal ablation based on the electroporation phenomenon. The delivery of direct electric current into cells using short pulses for microseconds results in the disruption of cell membrane integrity and creation of nanopores, which can be temporary (reversible electroporation) or permanent (IRE). The permanent nanopores result in the loss of cells' homeostatic mechanisms, thereby inducing cell death. ${ }^{53-56}$ Some investigators have evaluated IRE ablation in the liver, lung, prostate, and kidney. ${ }^{57-61}$ Interestingly, several unique characteristics of IRE ablation have been reported, including its capability of preserving the integrity of adjacent nearby structures and lack of a heat sink effect. ${ }^{59,60}$ Needless to say, these alluring advantages make IRE a potential choice for tumor ablation near vascular structures or thermally sensitive areas.

Another alternative treatment modality under investigation is light-activated drug therapy; activating talaporfin sodium that has the ability to concentrate in tumors following intravenous administration. Upon the activation of talaporfin sodium, through a percutaneously inserted light-emitting activator inside the tumor under imaging guidance, singlet oxygen is produced which causes oxidation and tumor blood vessel occlusion, resulting in cell death. ${ }^{62}$

In conclusion, the image-guided locoregional therapies have a key role in HCC management. Nowadays, these therapies are more frequently used with curative intent in surgical candidates (as a bridge before surgical resection or liver transplantation) or for nonsurgical candidates, as monotherapy or in combination with other therapies.

Finally, continuous clinical and translational research is of the utmost importance to better outline the indications and outcomes of monotherapy or combined therapy aiming to increase disease control and improve survival.

\section{Acknowledgment}

We would like to acknowledge Dr Michael J Wallace for his guidance and support in addition to his great effort for this publication. Dr Michael J Wallace passed away on May 31, 2016.

\section{Disclosure}

The authors report no conflicts of interest in this work.

\section{References}

1. Jemal A, Bray F, Center MM, Ferlay J, Ward E, Forman D. Global cancer statistics. CA Cancer J Clin. 2011;61(2):69-90.

2. Bruix J, Sherman M; American Association for the Study of Liver Disease. Management of hepatocellular carcinoma: an update. Hepatology 2011;53(3):1020-1022. 
3. Lencioni R. Loco-regional treatment of hepatocellular carcinoma. Hepatology. 2010;52(2):762-773.

4. Livraghi T, Bolondi L, Lazzaroni S, et al. Percutaneous ethanol injection in the treatment of hepatocellular carcinoma in cirrhosis. A study on 207 patients. Cancer. 1992;69(4):925-929.

5. Sala M, Llovet JM, Vilana R, et al. Initial response to percutaneous ablation predicts survival in patients with hepatocellular carcinoma. Hepatology. 2004;40(6):1352-1360.

6. Shiina S, Teratani T, Obi S, et al. A randomized controlled trial of radiofrequency ablation with ethanol injection for small hepatocellular carcinoma. Gastroenterology. 2005;129(1):122-130.

7. Lin SM, Lin CJ, Lin CC, Hsu CW, Chen YC. Randomised controlled trial comparing percutaneous radiofrequency thermal ablation, percutaneous ethanol injection, and percutaneous acetic acid injection to treat hepatocellular carcinoma of $3 \mathrm{~cm}$ or less. Gut. 2005;54(8): $1151-1156$

8. Ahrar K, Matin S, Wood CG, et al. Percutaneous radiofrequency ablation of renal tumors: technique, complications, and outcomes. J Vasc Interv Radiol. 2005;16(5):679-688.

9. Hong SN, Lee SY, Choi MS, et al. Comparing the outcomes of radiofrequency ablation and surgery in patients with a single small hepatocellular carcinoma and well-preserved hepatic function. J Clin Gastroenterol. 2005;39(3):247-252.

10. Cho CM, Tak WY, Kweon YO, et al. [The comparative results of radiofrequency ablation versus surgical resection for the treatment of hepatocellular carcinoma]. Korean J Hepatol. 2005;11(1):59-71. Korean.

11. Zhou DC, Geng XP, Zhu LX, Zhao HC, Liu FB, Zhao YJ. [Percutaneous radiofrequency ablation versus hepatic resection for small hepatocellular carcinoma: a meta analysis]. Zhonghua wai ke za zhi. 2011;49(12): 1132-1136. Chinese.

12. Liu Z, Zhou Y, Zhang P, Qin H. Meta-analysis of the therapeutic effect of hepatectomy versus radiofrequency ablation for the treatment of hepatocellular carcinoma. Surg Laparosc Endosc Percutan Tech. 2010; 20(3):130-140.

13. Chen MS, Li JQ, Zheng Y, et al. A prospective randomized trial comparing percutaneous local ablative therapy and partial hepatectomy for small hepatocellular carcinoma. Ann Surg. 2006;243(3): 321-328.

14. Huang J, Yan L, Cheng Z, et al. A randomized trial comparing radiofrequency ablation and surgical resection for HCC conforming to the Milan criteria. Ann Surg. 2010;252(6):903-912.

15. Feng K, Yan J, Li X, et al. A randomized controlled trial of radiofrequency ablation and surgical resection in the treatment of small hepatocellular carcinoma. J Hepatol. 2012;57(4):794-802.

16. Lu MD, Kuang M, Liang LJ, et al. [Surgical resection versus percutaneous thermal ablation for early-stage hepatocellular carcinoma: a randomized clinical trial]. Zhonghua yi xue za zhi. 2006;86(12):801-805. Chinese.

17. Livraghi T, Meloni F, Di Stasi M, et al. Sustained complete response and complications rates after radiofrequency ablation of very early hepatocellular carcinoma in cirrhosis: is resection still the treatment of choice? Hepatology. 2008;47(1):82-89.

18. Lubner MG, Brace CL, Hinshaw JL, Lee FT Jr. Microwave tumor ablation: mechanism of action, clinical results, and devices. J Vasc Interv Radiol. 2010;21(8 Suppl):S192-S203.

19. Liang P, Wang Y. Microwave ablation of hepatocellular carcinoma. Oncology. 2007;72(Suppl 1):124-131.

20. Poggi G, Montagna B, DI Cesare P, Riva G, Bernardo G, Mazzucco M, Riccardi A. Microwave ablation of hepatocellular carcinoma using a new percutaneous device: preliminary results. Anticancer Res. 2013; 33(3):1221-1227.

21. Zhang L, Wang N, Shen Q, Cheng W, Qian GJ. Therapeutic efficacy of percutaneous radiofrequency ablation versus microwave ablation for hepatocellular carcinoma. PLoS One. 2013;8(10):e76119.

22. Lee SM, Won JY, Lee DY, et al. Percutaneous cryoablation of small hepatocellular carcinomas using a 17-gauge ultrathin probe. Clinical Radiol. 2011;66(8):752-759.
23. Bageacu S, Kaczmarek D, Lacroix M, Dubois J, Forest J, Porcheron J. Cryosurgery for resectable and unresectable hepatic metastases from colorectal cancer. Eur J Surg Oncol. 2007;33(5):590-596.

24. Seifert JK, France MP, Zhao J, Bolton EJ, Finlay I, Junginger T, Morris DL. Large volume hepatic freezing: association with significant release of the cytokines interleukin- 6 and tumor necrosis factor a in a rat model. World J Surg. 2002;26(11):1333-1341.

25. Sheen AJ, Poston GJ, Sherlock DJ. Cryotherapeutic ablation of liver tumours. Br J Surg. 2002;89(11):1396-1401.

26. Lammer J, Malagari K, Vogl T, et al. Prospective randomized study of doxorubicin-eluting-bead embolization in the treatment of hepatocellular carcinoma: results of the PRECISION V study. Cardiovasc Interv Radiol. 2010;33(1):41-52.

27. Vogl TJ, Lammer J, Lencioni R, et al. Liver, gastrointestinal, and cardiac toxicity in intermediate hepatocellular carcinoma treated with PRECISION TACE with drug-eluting beads: results from the PRECISION V randomized trial. AJR Am J Roentgenol. 2011;197(4):W562-W570.

28. Llovet JM, Bruix J. Systematic review of randomized trials for unresectable hepatocellular carcinoma: chemoembolization improves survival. Hepatology. 2003;37(2):429-442.

29. Burrel M, Reig M, Forner A, et al. Survival of patients with hepatocellular carcinoma treated by transarterial chemoembolisation (TACE) using drug eluting beads. Implications for clinical practice and trial design. J Hepatol. 2012;56(6):1330-1335.

30. Yao FY, Kinkhabwala M, LaBerge JM, et al. The impact of pre-operative loco-regional therapy on outcome after liver transplantation for hepatocellular carcinoma. Am J Transplant. 2005;5(4 Pt 1):795-804.

31. Yao FY, Hirose R, LaBerge JM, et al. A prospective study on downstaging of hepatocellular carcinoma prior to liver transplantation. Liver Transplant. 2005;11(12):1505-1514.

32. Meyer T, Kirkwood A, Roughton M, et al. A randomised phase II/III trial of 3-weekly cisplatin-based sequential transarterial chemoembolisation vs embolisation alone for hepatocellular carcinoma. Br J Cancer. 2013;108(6):1252-1259.

33. Kluger MD, Halazun KJ, Barroso RT, et al. Bland embolization versus chemoembolization of hepatocellular carcinoma before transplantation. Liver Transplant. 2014;20(5):536-543.

34. Brown KT, Do RK, Gonen M, et al. Randomized trial of hepatic artery embolization for hepatocellular carcinoma using doxorubicin-eluting microspheres compared with embolization with microspheres alone. J Clin Oncol. 2016;34(17):2046-2053.

35. Ingold JA, Reed GB, Kaplan HS, Bagshaw MA. Radiation hepatitis. Am J Roentgenol Radium Ther Nucl Med. 1965;93:200-208.

36. Lawrence TS, Robertson JM, Anscher MS, Jirtle RL, Ensminger WD, Fajardo LF. Hepatic toxicity resulting from cancer treatment. Int J Radiat Oncol Biol Phys. 1995;31(5):1237-1248.

37. Mazzaferro V, Sposito C, Bhoori S, et al. Yttrium-90 radioembolization for intermediate-advanced hepatocellular carcinoma: a phase 2 study. Hepatology. 2013;57(5):1826-1837.

38. Salem R, Lewandowski RJ, Mulcahy MF, et al. Radioembolization for hepatocellular carcinoma using Yttrium-90 microspheres: a comprehensive report of long-term outcomes. Gastroenterology. 2010;138(1):52-64.

39. Veltri A, Moretto P, Doriguzzi A, Pagano E, Carrara G, Gandini G. Radiofrequency thermal ablation (RFA) after transarterial chemoembolization (TACE) as a combined therapy for unresectable non-early hepatocellular carcinoma (HCC). Eur Radiol. 2006;16(3):661-669.

40. Rossi S, Garbagnati F, Lencioni R, et al. Percutaneous radio-frequency thermal ablation of nonresectable hepatocellular carcinoma after occlusion of tumor blood supply. Radiology. 2000;217(1):119-126.

41. Morimoto M, Numata K, Kondo M, Moriya S, Morita S, Maeda S, Tanaka K. Radiofrequency ablation combined with transarterial chemoembolization for subcapsular hepatocellular carcinoma: a prospective cohort study. Eur J Radiol. 2013;82(3):497-503.

42. Morimoto M, Numata K, Kondou M, Nozaki A, Morita S, Tanaka K. Midterm outcomes in patients with intermediate-sized hepatocellular carcinoma: a randomized controlled trial for determining the efficacy of radiofrequency ablation combined with transcatheter arterial chemoembolization. Cancer. 2010;116(23):5452-5460. 
43. Lencioni R, Crocetti L, Petruzzi P, et al. Doxorubicin-eluting beadenhanced radiofrequency ablation of hepatocellular carcinoma: a pilot clinical study. J Hepatol. 2008;49(2):217-222.

44. Yamasaki T, Kurokawa F, Shirahashi H, Kusano N, Hironaka K, Okita K. Percutaneous radiofrequency ablation therapy for patients with hepatocellular carcinoma during occlusion of hepatic blood flow. Comparison with standard percutaneous radiofrequency ablation therapy. Cancer. 2002;95(11):2353-2360.

45. Llovet JM, Ricci S, Mazzaferro V, et al. Sorafenib in advanced hepatocellular carcinoma. $N$ Engl J Med. 2008;359(4):378-390.

46. Cheng AL, Kang YK, Chen Z, et al. Efficacy and safety of sorafenib in patients in the Asia-Pacific region with advanced hepatocellular carcinoma: a phase III randomised, double-blind, placebo-controlled trial. Lancet Oncol. 2009;10(1):25-34.

47. Chow PK, Poon DY, Khin MW, et al. Multicenter phase II study of sequential radioembolization-sorafenib therapy for inoperable hepatocellular carcinoma. PLoS One. 2014;9(3):e90909.

48. Pawlik TM, Reyes DK, Cosgrove D, Kamel IR, Bhagat N, Geschwind JF. Phase II trial of sorafenib combined with concurrent transarterial chemoembolization with drug-eluting beads for hepatocellular carcinoma. J Clin Oncol. 2011;29(30):3960-3967.

49. Park JW, Koh YH, Kim HB, et al. Phase II study of concurrent transarterial chemoembolization and sorafenib in patients with unresectable hepatocellular carcinoma. J Hepatol. 2012;56(6):1336-1342.

50. Choi GH, Shim JH, Kim MJ, et al. Sorafenib alone versus sorafenib combined with transarterial chemoembolization for advanced-stage hepatocellular carcinoma: results of propensity score analyses. Radiology. 2013;269(2):603-611.

51. Qu XD, Chen CS, Wang JH, et al. The efficacy of TACE combined sorafenib in advanced stages hepatocellullar carcinoma. BMC Cancer. 2012;12:263.
52. Mahvash A, Murthy R, Odisio BC, et al. Yttrium-90 resin microspheres as an adjunct to sorafenib in patients with unresectable hepatocellular carcinoma. J Hepatocell Carcinoma. 2016;3:1-7.

53. Miller L, Leor J, Rubinsky B. Cancer cells ablation with irreversible electroporation. Technol Cancer Res Treat. 2005;4(6):699-705.

54. Rubinsky B. Irreversible electroporation in medicine. Technol Cancer Res Treat. 2007;6(4):255-260.

55. Rubinsky B, Onik G, Mikus P. Irreversible electroporation: a new ablation modality - clinical implications. Technol Cancer Res Treat. 2007;6(1):37-48.

56. Edd JF, Horowitz L, Davalos RV, Mir LM, Rubinsky B. In vivo results of a new focal tissue ablation technique: irreversible electroporation. IEEE Trans Biomed Eng. 2006;53(7):1409-1415.

57. Ben-David E, Appelbaum L, Sosna J, Nissenbaum I, Goldberg SN. Characterization of irreversible electroporation ablation in in vivo porcine liver. AJR Am J Roentgenol. 2012;198(1):W62-W68.

58. Deodhar A, Monette S, Single GW Jr, et al. Percutaneous irreversible electroporation lung ablation: preliminary results in a porcine model. Cardiovasc Intervent Radiol. 2011;34(6):1278-1287.

59. Charpentier KP, Wolf F, Noble L, Winn B, Resnick M, Dupuy DE Irreversible electroporation of the liver and liver hilum in swine. $H P B$ (Oxford). 2011;13(3):168-173.

60. Onik G, Mikus P, Rubinsky B. Irreversible electroporation: implications for prostate ablation. Technol Cancer Res Treat. 2007;6(4): 295-300.

61. Pech M, Janitzky A, Wendler JJ, et al. Irreversible electroporation of renal cell carcinoma: a first-in-man phase I clinical study. Cardiovasc Intervent Radiol. 2011;34(1):132-138.

62. Lencioni R, Cioni D, Della Pina C, Crocetti L. Hepatocellular carcinoma: new options for image-guided ablation. J Hepatobiliary Pancreat Sci. 2010;17(4):399-403.
Journal of Hepatocellular Carcinoma

\section{Publish your work in this journal}

The Journal of Hepatocellular Carcinoma is an international, peerreviewed, open access journal that offers a platform for the dissemination and study of clinical, translational and basic research findings in this rapidly developing field. Development in areas including, but not limited to, epidemiology, vaccination, hepatitis therapy, pathology and

\section{Dovepress}

molecular tumor classification and prognostication are all considered for publication. The manuscript management system is completely online and includes a very quick and fair peer-review system, which is all easy to use. Visit http://www.dovepress.com/testimonials.php to read real quotes from published authors. 